\title{
ANÁLISE ACÚSTICA DA VOZ DO IDOSO: CARACTERIZAÇÃO DAFREQÜÊNCIA FUNDAMENTAL
}

\author{
Acoustic analysis of aging voice: \\ fundamental frequency characterization
}

\author{
Erika Mifune ${ }^{(1)}$, Vanessa da Silva Saraiva Justino ${ }^{(2)}$, Zuleica Camargo ${ }^{(3)}$, Fabiana Gregio ${ }^{(4)}$
}

\begin{abstract}
RESUMO
Objetivo: estimar a freqüência fundamental ( $\mathrm{fO}$ ) de ambos os sexos na terceira idade e suas correlações perceptivo-auditivas (distinção de sexos e faixa etária). Métodos: quatro indivíduos do sexo masculino e quatro do feminino, idades entre 60 e 76 anos, sem alteração de aparelho fonador, foram submetidos à gravação de leitura de texto (duas repetições). Os valores de $f 0$ foram mensurados na vogal [a] em sílabas tônicas (T) e pré-tônicas (PT) do mesmo vocábulo (no início e no fim de sentenças) e submetidos à análise estatística. As amostras foram submetidas à análise perceptivo-auditiva (julgamentos de sexo e faixa etária) por 60 juízes. Resultados: as médias de f0 em PT foram 114,14 Hz em início de sentença e 102,71 Hz em final no sexo masculino e 151 Hz em início e 146,87 Hz em final no sexo feminino. Para T, os valores foram $117,42 \mathrm{~Hz}$ em início de sentença e $92,85 \mathrm{~Hz}$ no sexo masculino em final e $175 \mathrm{~Hz}$ em início de sentença e $122,50 \mathrm{~Hz}$ no sexo feminino em final. Houve diferença significativa entre os sexos, bem como entre os falantes do mesmo sexo com relação à faixa etária adulta, especialmente para o feminino. Todos os falantes foram julgados corretamente quanto ao sexo, com faixa etária referida como inferior à real. Conclusão: houve diferença significante de medidas de $\mathrm{f} 0 \mathrm{em}$ idosos entre sexos masculino e feminino em relação à faixa etária adulta, tendo o último sexo apresentado declínio mais acentuado, sem interferências no julgamento de sexo e de faixa etária.
\end{abstract}

DESCRITORES: Acústica da Fala; Idoso; Voz; Identidade de sexo; Percepção Auditiva

\section{INTRODUÇÃO}

O envelhecimento populacional é hoje um fenômeno universal, tanto dos países desenvolvidos como, de modo crescente, do Terceiro Mundo ${ }^{1}$. Vários autores tentaram definir a terceira idade com base em diferentes conceitos. De acordo com a Organização Mundial de Saúde, nos países em desenvolvimento, adota-se sessenta anos como idade para definir a

(1) Fonoaudióloga da Plus Medicina do Trabalho; Especialista em Audiologia Clinica.

(2) Fonoaudióloga da clínica SERKAR serviços médicos e do SAE (Serviços de Análises Especializadas) laboratório; Especialista em Audiologia Clínica.

(3) Fonoaudióloga; Professora Assistente-Doutora do Departamento de Lingüística da Faculdade de Comunicação e Filosofia da Pontifícia Universidade Católica de São Paulo; Doutora em Lingüística Aplicada e Estudos da Linguagem pela Pontifícia Universidade Católica de São Paulo.

(4) Fonoaudióloga do Laboratório de Fala do CEFAC - Saúde e Educação; Mestre em Lingüística Aplicada e Estudos da Linguagem pela Pontifícia Universidade Católica de São Paulo. população idosa ${ }^{2}$. Anteriormente, foram estabelecidos critérios diferenciados que incluíam desde a faixa etária (a partir dos sessenta e cinco anos) até dados estatísticos como o declínio de várias funções vitais ${ }^{3}$.

O envelhecimento saudável ou senescência é aquele no qual as mudanças funcionais são gradativas e permitem que as células tenham condições de adaptação ao novo ritmo, sem ruptura, mantendo qualidade de vida ${ }^{1}$. Com a passagem dos anos, o indivíduo sofre diminuição nas habilidades do corpo, registrando perda no controle neuromuscular e dos processos perceptivos, o que também ocorre no aparelho fonador, levando a mudanças significativas dos parâmetros vocais ${ }^{2-5}$, em conseqüência do declínio das funções dos órgãos da fala ${ }^{6}$.

As mudanças associadas à idade são altamente específicas, não só para cada indivíduo, mas para cada um dos órgãos. Começam em diferentes partes do corpo, momentos diversos e com um ritmo de mudanças distintas ${ }^{7}$. Dessa forma, há a tendência 
de declínio das funções dos órgãos, porém, variável entre idosos da mesma faixa etária.

O controle da voz depende de um delicado balanço pulmonar, laríngeo e de elementos articulatórios e ressonantais, os quais, por sua vez, dependem da integridade funcional e estrutural dos sistemas muscular, neural, endocrinológico e esquelético. Certas alterações fisiológicas podem modificar o processo natural de produção da fala. Os parâmetros mais freqüentemente citados são redução da capacidade vital pulmonar, osteoporose da coluna espinhal e costelas, ossificação das cartilagens da laringe e atrofia muscular e das mucosas das vias respiratórias ${ }^{8}$.

No mecanismo respiratório, as trocas gasosas no pulmão também se modificam com o avanço da idade. No que se refere às interferências na fala, destacam-se várias mudanças, tais como: calcificação das cartilagens costais, mudanças nas articulações dos ossos das vértebras, alteração das relações de estruturas por motivo de mudança postural e tônus muscular reduzido ${ }^{7,9}$.

No envelhecimento, os músculos laríngeos também são comprometidos e sofrem alterações, as quais são atribuídas à diminuição da vascularização 2. Os músculos extrínsecos laríngeos podem perder sua elasticidade e tonicidade e a laringe passa a ocupar uma posição mais baixa no pescoço, processo conhecido como ptose laríngea ${ }^{1,6,9,10}$. Ocorre também o estiramento excessivo dos ligamentos de aparatos de suspensão e atrofia das fibras musculares do pescoço ${ }^{9}$.

No caso das cartilagens laríngeas, a perda de elasticidade manifesta-se como progressiva ossificação 11-13, com diminuição de mobilidades das articulações laríngeas, acompanhada de atrofia das pregas vestibulares, mudanças na cobertura das pregas vocais $\mathrm{e}$ aumento da fragilidade dos vasos sanguíneos da laringe, resultando em tendência a hemorragia submucosa ${ }^{5,9}$.

A partir dos 20 anos, na mulher, há intensificação da ossificação das cartilagens laríngeas, que ficam mais rígidas e menos distensíveis ${ }^{6}$. As alterações mais marcantes na estrutura de pregas vocais, em ambos os sexos, foram registradas na lâmina própria da prega vocal, o que tende a provocar espessamento e edema. O aumento das fibras de colágeno e a diminuição do ácido hialurônico provocam alterações vibratórias ${ }^{14}$.

No sexo masculino, foram apontadas calcificação mais intensa ${ }^{8}$ a partir da terceira década de vida ${ }^{1}$, mudança da espessura da camada intermediária das pregas vocais (mais fina), enquanto a camada profunda, ao contrário, fica espessa, pois as fibras colágenas tendem a se tornar mais espessas e densas ${ }^{1,6,8}$. Às vezes, ocorre a deterioração do contorno da camada profunda da lâmina própria ${ }^{1,8,15}$.
Estudo explorando as mudanças da qualidade vocal inerentes a mudanças de elementos glóticos e supraglóticos do aparelho fonador por meio de correlatos acústicos de longo termo e perceptivo-auditivos, com achados de padrões altamente individualizados entre si, não revelou agrupamentos em função dos sexos masculino e feminino ${ }^{16}$.

Em ambos os sexos, a freqüência fundamental (f0) da fala foi estudada em jovens adultos até a terceira idade. Diferentes padrões de mudança com a idade podem ser observados tanto em homens como em mulheres ${ }^{17}$. Vários estudos enfocaram as modificações que ocorrem na voz com o processo de envelhecimento, tendo-se destacado especialmente o aumento de fo nos homens ${ }^{1,2,18,19} \mathrm{ea}$ manutenção ou redução da f0 nas mulheres ${ }^{1,2,19}$, fazendo com que as vozes dos indivíduos idosos se parecessem entre si e perdessem parte da possibilidade de identificação referente ao sexo do falante ${ }^{1,5,18}$. Outros confirmam o mesmo, porém afirmam que a f0 permanece praticamente estável no sexo masculino ${ }^{20}$.

Especificamente, a f0 da fala pode apresentar-se rebaixada nos adultos jovens do sexo masculino até a meia-idade e aumentar na passagem para a terceira idade. A f0 da fala nas mulheres fica constante até os 20 anos de idade e após os 50 anos tende a revelar uma queda ${ }^{17}$. Presumivelmente, a queda dos níveis hormonais pelo processo de envelhecimento leva a voz feminina a tornar-se mais grave e a tessitura vocal mais restrita ${ }^{18}$, como resultado de edema vocal ${ }^{5,21}$. Estudo explorando a percepção auditiva da voz na população idosa do sexo feminino revelou que a mesma não percebe o agravamento da freqüência, em oposição aos fonoaudiólogos ${ }^{22}$.

Algumas pesquisas evidenciaram o contrário, a tendência ao aumento de $\mathrm{f} 0$ da fala em mulheres com idade avançada, entretanto é referida mudança sutil na f0 da fala durante a passagem da meia-idade para a terceira idade ${ }^{17}$.

A percepção de fo também envolveu a investigação de freqüências dentro da emissão vocal que seriam relevantes, tanto para vozes masculinas como femininas, com base na informação lingüística, vinculada às modulações de fo na fala encadeada ${ }^{23}$. Em pesquisa com estímulos de vogais sintetizadas, o julgamento do sexo esteve baseado na f0, mesmo que as informações entre fo e formantes fossem contrastantes ${ }^{24}$.

Para o português brasileiro, estimativas de valores de f0 foram oferecidas por dois estudos para falantes adultos dos sexos masculino e feminino ${ }^{25,26}$. Ambos os estudos compararam as medidas de f0 obtidas a partir amostras de leitura de texto padronizado e de contagem de números. Para o grupo do sexo masculino (150 homens normais com idade de 17 a 30 anos, 
sem histórico ou queixas de alterações laríngeas), a média do valor de f0 foi $134.9 \pm$ 17.9 Hz para leitura e de $130.5 \pm 18.5 \mathrm{~Hz}$ para contagem, com diferença estatisticamente significativa ${ }^{25}$.

Para o grupo do sexo feminino (140 sujeitos normais com idade de 17 a 30 anos, sem histórico ou queixas de alterações laríngeas), a média do valor de f0 obtida para leitura foi $213.9 \mathrm{~Hz}$ (DP $=9.0 \mathrm{~Hz})$ e $200.1 \mathrm{~Hz}(\mathrm{DP}=26.4 \mathrm{~Hz})$ para contagem de números ${ }^{26}$.

Diante dos achados relatados, este estudo apresenta o objetivo de estimar a freqüência fundamental (f0) de ambos os sexos na terceira idade, procurando discutir as correlações ao plano da percepção, especialmente com relação à distinção de sexos e indicação de faixa etária nas vozes dos indivíduos idosos.

\section{MÉTODOS}

O grupo estudado foi composto por oito indivíduos falantes do português brasileiro, na faixa etária acima de sessenta anos, limite para se considerar a população idosa em países em desenvolvimento ${ }^{2}$. 0 grupo estudado foi dividido em dois subgrupos, compostos por quatro indivíduos do sexo masculino (denominados A, B, C e D, com idades variando de 60 e 76 anos, média $=69,8)$ e quatro do sexo feminino (denominados E, F, G e H, com idades variando de 71 e 75 anos, média = 73).

Foram excluídos do estudo os indivíduos com alterações decorrentes de doenças neurológicas, periféricas ou centrais ou que tiveram sofrido intercorrências no aparelho fonador, tais como cirurgias ou traumas que implicassem mudanças anatômicas.

A seleção da casuística partiu da aplicação prévia de um questionário que buscou investigar queixa de alteração vocal e outros aspectos que pudessem interferir na qualidade vocal, constituindo os critérios de exclusão acima delineados. Nenhum dos falantes passou por tratamento vocal e relatou esforço ao falar. Três indivíduos $(A, C$ e $E)$ referiram passado otológico, dois indivíduos $(\mathrm{G}$ e H$)$ distúrbio hormonal e um distúrbio digestivo (D). Quanto aos hábitos, um (H) relatou ter fumado durante muito tempo, porém não fumava mais no momento da coleta, um (C) é fumante. Dois participantes $(\mathrm{G} \mathrm{e} \mathrm{H})$ praticam atividades físicas e dois $(\mathrm{B}$ e $\mathrm{H}$ ) participam de coral.

A coleta de dados incluiu a gravação de amostras de fala do texto padronizado. O texto utilizado teve predomínio de sons sonoros e foi elaborado no LIAAC (Laboratório Integrado de Análise Acústica) Faculdade de Comunicação e Filosofia da Pontifícia Universidade Católica de São Paulo ${ }^{27}$. Durante as gravações, todos os falantes realizaram a mesma seqüência de tarefas constando de registro de duas leituras do mesmo texto.
As amostras de fala foram coletadas e digitalizadas no Laboratório de Rádio da COMFIL (Faculdade de Comunicação e Filosofia) da Pontifícia Universidade Católica de São Paulo, contando com o apoio de profissionais técnicos e equipamentos da gravação. Foi utilizado microfone Shure, modelo $\mathrm{M}-7$, fixado a $10 \mathrm{~cm}$ da lateral direita da boca do falante, que permaneceu sentado. A gravação foi monitorada para que o nível de digitalização fosse adequado à análise.

O microfone foi conectado à mesa de som da marca Shure, modelo M267, direcionando os estímulos registrados ao software Sound Forge 6.0. Tais amostras também foram registradas em $m$ freqüência de amostragem de $22050 \mathrm{~Hz}, 16$ bits de quantização, formato .wav.

As amostras de fala da emissão "arara" foram destacadas do texto e analisadas no LIAAC (Laboratório Integrado de Análise Acústica) - Faculdade de Comunicação e Filosofia da Pontifícia Universidade Católica de São Paulo, envolvendo na inspeção em curto termo dos traçados FFT (Fast Fourier Transform) e extração dos valores de f0.

Para a extração dos valores da f0 referentes à vogal [a] dos estímulos acima citados, foi utilizado no software Multispeech da Kay Elemetrics Corporation do LIAAC (PUC/SP), seguindo os parâmetros de 1024 pontos (tamanho da análise), sem suavização, com pré-ênfase de 0.098, janelamento hanning, intensidade mínima de $0 \mathrm{~dB}$ e máxima de $80 \mathrm{~dB}$ e faixa de freqüência de 0 a 11025 $\mathrm{Hz}$. Foram analisadas, no caso das repetições do vocábulo "arara", as vogais nas sílabas pré-tônicas (arara) e tônicas (arara) nas duas repetições da leitura. No texto, o referido vocábulo aparecia duas vezes, uma no início e outra no final da sentença ("A arara exibiu os dons maravilhosos .." e "A líder das aves é uma bela e animada arara").

De cada emissão vocálica foi selecionado trecho da amostra correspondente ao período estacionário da vogal. A partir do traçado do espectro FFT, foi identificado o pico do primeiro harmônico em termos de freqüência $(\mathrm{Hz})$ do componente fundamental (fO). No procedimento de inspeção das ondas e geração de espectros e espectrogramas, os pesquisadores apontavam a ocorrência de ajustes de qualidade vocal, como voz crepitante, áspera ou soprosa e a ocorrência de instabilidades de curto termo, como quebras ou diplofonia.

Do ponto de vista de julgamento perceptivo-auditivo, 60 graduandos do curso de Fonoaudiologia da Pontifícia Universidade Católica de São Paulo avaliaram os estímulos contendo trechos do texto das duas leituras de cada falante, quanto ao sexo do falante e estimativa de faixa etária, não tendo sido informados previamente sobre tais características. A apresentação dos estímulos ocorreu de for- 
ma aleatória em dezesseis faixas de áudio (duas para cada falante dos grupos estudados), totalizando 480 julgamentos para as amostras de cada sexo.

Esta pesquisa foi aprovada pelo Comitê de Ética e Pesquisa da Pontifícia Universidade Católica de São Paulo sob o número 222/02, tendo sido considerada sem risco e com necessidade de consentimento livre e esclarecido.

Os resultados foram submetidos à análise estatística por meio do teste T de Student, com nível de significância de 0,05, tomando-se como base as diferenças de valores de f0 entre sexos para as diferentes modalidades de emissões (vogal em contexto de sílabas pré-tônica e tônica em vocábulos em posição inicial e final na sentença). Os dados também foram comparados às referências da literatura para estimativas das medidas de f0 em leituras para adultos jovens de ambos os sexos estudados ${ }^{25,26}$.

\section{RESULTADOS}

Os resultados obtidos na análise das amostras das vozes dos sujeitos selecionados passam a ser apresentados enquanto valores de f0 e dados de avaliação perceptivo-auditiva.

Os valores de f0 para as emissões da vogal [a] em contexto encadeado no vocábulo "arara" são expostas de forma diferenciada para o vocábulo posicionado no início (Tabelas 1 e 2) e no final de sentença (Tabelas 3 e 4 ) e para os sexos masculino (Tabelas 1 e 3) e feminino (Tabelas 2 e 4).

Conforme exposto na Tabela 1 , há menção de ajustes de voz crepitante em dois falantes do sexo masculino, apenas em uma leitura e, em sua maioria, na sílaba pré-tônica (total de três vogais com ajustes de voz crepitante). As médias de f0 para vocábulo posicionado em início de sentença na sílaba pré-tônica foram de $114,14 \mathrm{~Hz}(\mathrm{DP}=40,03)$ e de $117,42 \mathrm{~Hz}(\mathrm{DP}=32,84 \mathrm{~Hz})$ na sílaba tônica.

A Tabela 2 revela que três falantes do sexo feminino apresentaram ajuste de voz crepitante somente na sílaba pré-tônica, no início da sentença e apenas em uma leitura (total de 3 vogais com ajustes de voz crepitante). As médias de fo obtidas no sexo feminino no vocábulo em início de sentença na sílaba prétônica foram $151 \mathrm{~Hz}(\mathrm{DP}=19,09)$ de $175 \mathrm{~Hz}(\mathrm{DP}=$ 9,58 Hz na sílaba tônica).

Não houve diferenças estatisticamente significante entre os valores de f0 para os sexos masculino e feminino para as emissões de [a] em duas repetições em vogal pré-tônica (arara) para o vocábulo em posição inicial da sentença. Para o mesmo contexto de vocábulo em início de sentença, houve diferença es- tatística entre medidas de f0 entre sexos para as duas repetições em sílaba tônica (arara) com respectivos valores de p em 0,024 e 0,029.

Os valores médios de f0 para falantes do sexo masculino no vocábulo em final de sentença (Tabela 3) na sílaba pré-tônica foram de $102,71 \mathrm{~Hz}$ (DP= $22,02 \mathrm{~Hz})$ e de $92,85 \mathrm{~Hz}(\mathrm{DP}=20,64)$ para a sílaba tônica.

Conforme indicado na Tabela 4 foram encontrados três falantes do sexo feminino com ajustes de voz crepitante nas duas leituras, tanto nas sílabas pré-tônicas, como nas tônicas (total de onze vogais) do vocábulo situado no final da sentença. Foram evidenciados resultados das médias de f0 para o vocábulo na posição final de sentença na silaba pré-tônica em $146,87 \mathrm{~Hz}(\mathrm{DP}=20,80)$ e de $122,50 \mathrm{~Hz}(\mathrm{DP}=$ 18,11) na sílaba tônica.

Para vogais em vocábulos posicionados no fim da sentença as diferenças de valores de f0 entre os sexos masculino e feminino foram estatisticamente significantes em uma repetição de sílaba pré-tônica e uma de sílaba tônica, com respectivos valores de $p$ situados em 0,001 e 0,012 para as duas repetições.

Os dados comparativos de f0 para ambos os sexos são apresentados na Figura 1. Na comparação com estudos de f0 para indivíduos adultos jovens ${ }^{25,26}$, os valores encontrados revelaram para o sexo feminino diferenças significativas em sete das oito vogais avaliadas (valores de $\mathrm{p}$ situados respectivamente em 0,007; 0,009 e 0,000 para as duas repetições de sílaba pré-tônica e uma da tônica em início de sentença, e em 0,001; 0,034; 0,001 e 0,066 para as duas repetições de sílaba pré-tônica e duas da tônica em final de sentença). Para o sexo masculino, as diferenças ocorreram em uma emissão em início de sentença (valor de p situado em 0,024 para sílaba tônica) e em duas emissões de [a] em final de sentença (valores respectivos de $\mathrm{p}$ situados em 0,026 para prétônica e em 0,017 para tônica).

Os achados de julgamentos perceptivo-auditivos referentes à faixa etária são apresentados na Figura 2, enquanto indicativos da idade real e daquela atribuída aos falantes. Para todos os indivíduos estudados, a faixa etária atribuída foi inferior à real em, no mínimo, uma década e, no máximo, três. Os falantes $A, B, C, D$, e F tiveram médias de idades atribuídas entre 11, 5 e 19,5 anos abaixo da real. Os falantes $\mathrm{E}$ e $\mathrm{H}$ tiveram médias de idades atribuídas em respectivas faixas de 29,5 e 22,5 anos abaixo da idade real. $O$ falante $G$ recebeu a indicação de média de idade inferior em 35 anos.

Quanto aos julgamentos de sexo dos falantes, os resultados são apresentados na Figura 3, com relação ao número total de acertos para os sexos masculino e feminino (480 julgamentos cada), revelando concordância em 474 julgamentos em cada sexo. 
Tabela 1 - Valores de f0, média e desvio-padrão para duas emissões de vogal [a] em posição pré-tônica e tônica do vocábulo "arara" no início da sentença para quatro falantes do sexo masculino (falantes A a D)

\begin{tabular}{llll}
\hline Falante & Leitura & $\begin{array}{l}\text { f0 }(\mathrm{Hz}) \\
\text { Vogal na sílaba } \\
\text { pré-tônica Arara }\end{array}$ & $\begin{array}{l}\text { f0 }(\mathrm{Hz}) \\
\text { Vogal na sílaba } \\
\text { Tônica Arara }\end{array}$ \\
\hline A & 1 & 114 & 808 \\
A & 2 & 808 & 80 \\
B & 1 & 808 & 114 \\
B & 2 & 80 & 114 \\
C & 1 & 103 & 114 \\
C & 2 & --- & -- \\
D & 1 & 171 & 160 \\
D & 2 & 171 & 160 \\
\hline Média & & 114,14 & 117,42 \\
DP & & 40,63 & 32,84 \\
\hline
\end{tabular}

Legenda: $-=$ não foi possível o registro de fo (o falante omitiu o vocábulo arara na leitura)

$8=$ ajuste de voz crepitante

Tabela 2 - Valores de fo, média e desvio-padrão para duas emissões de vogal [a] em posição prétônica e tônica do vocábulo "arara" no início da sentença para quatro falantes do sexo feminino (falantes $\mathrm{E} \mathrm{a} \mathrm{H}$ )

\begin{tabular}{llll}
\hline Falante & Leitura & $\begin{array}{l}\text { fo }(\mathrm{Hz}) \\
\text { Vogal na silaba } \\
\text { pré-tônica }\end{array}$ & $\begin{array}{l}\text { f0 }(\mathrm{Hz}) \\
\text { Vogal na silaba } \\
\text { Tônica }\end{array}$ \\
\hline E & 1 & 154 & 165 \\
E & 2 & 1548 & 186 \\
F & 1 & 171 & 171 \\
F & 2 & 1718 & 205 \\
G & 1 & 125 & 171 \\
G & 2 & 125 & 171 \\
H & 1 & 148 & 160 \\
H & 2 & 1608 & 171 \\
\hline Média & & 151 & 175 \\
DP & & 19,09 & 9,58 \\
\hline
\end{tabular}

Legenda: $8=$ ajuste de voz crepitante 
Tabela 3 - Valores de f0, média e desvio-padrão para duas emissões de vogal [a] em posição pré-tônica e tônica do vocábulo "arara" no final da sentença para quatro falantes do sexo masculino (falantes A a D)

\begin{tabular}{llll}
\hline Falante & Leitura & $\begin{array}{l}\text { f0 }(\mathrm{Hz}) \\
\text { Vogal na sílaba } \\
\text { pré-tônica Arara }\end{array}$ & $\begin{array}{l}\text { fo }(\mathrm{Hz}) \\
\text { Vogal na sílaba } \\
\text { Tônica Arara }\end{array}$ \\
\hline A & 1 & --- & 80 \\
A & 2 & 808 & --- \\
B & 1 & 988 & 83 \\
B & 2 & 838 & $62 ?$ \\
C & 1 & 103 & 103 \\
C & 2 & 93 & 83 \\
D & 1 & 114 & 114 \\
D & 2 & 148 & 125 \\
\hline Média & & 102,71 & 92,85 \\
DP & & 22,02 & 20,64 \\
\hline
\end{tabular}

Legenda: —= não foi possível o registro de fo (o falante omitiu o vocábulo arara na leitura) $8=$ ajuste de voz crepitante

Tabela 4 - Valores de f0, média e desvio-padrão para duas emissões de vogal [a] em posição prétônica e tônica do vocábulo "arara" no final da sentença para quatro falantes do sexo feminino

\begin{tabular}{llll}
\hline Falante & Leitura & $\begin{array}{l}\text { fo }(\mathrm{Hz}) \\
\text { Vogal na silaba } \\
\text { pré-tônica Arara }\end{array}$ & $\begin{array}{l}\text { f0 }(\mathrm{Hz}) \\
\text { Vogal na sílaba } \\
\text { Tônica Arara }\end{array}$ \\
\hline E & 1 & 1548 & 1328 \\
E & 2 & 838 & 838 \\
F & 1 & 1458 & 1248 \\
F & 2 & 145 & 1248 \\
G & 1 & 1668 & 1458 \\
G & 2 & 166 & 1508 \\
H & 1 & 150 & 119 \\
H & 2 & 166 & 103 \\
\hline Média & & 146,87 & 122,50 \\
DP & & 20,80 & 18,11 \\
\hline
\end{tabular}

Legenda: $8=$ ajuste de voz crepitante 


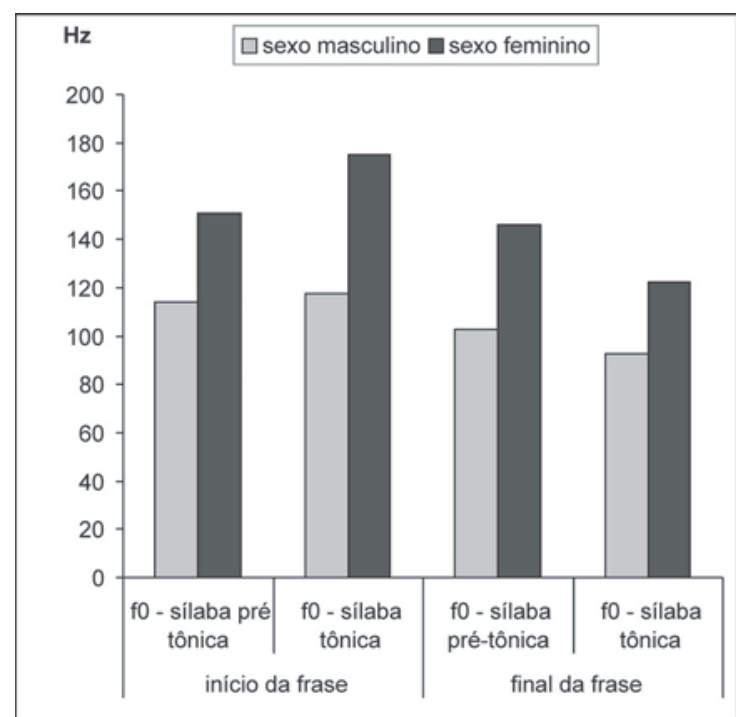

Figura 1 - Valores da média da f0 obtidos entre os indivíduos idosos do sexo feminino e masculino em emissões de padrão encadeado nos contextos de sílabas pré-tônicas e tônicas em posição inicial e final da sentença

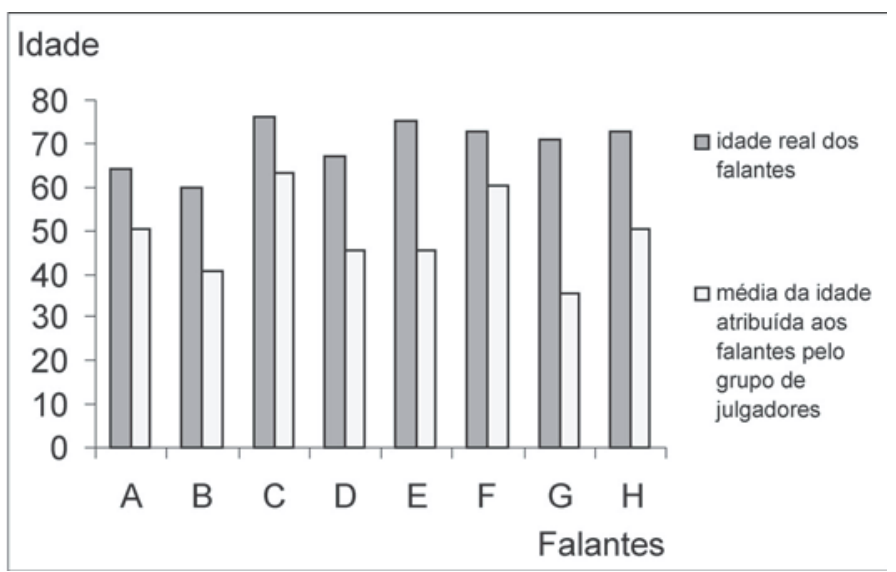

Figura 2 - Julgamento perceptivo-auditivo das amostras quanto à idade real e à idade atribuída aos falantes idosos dos sexos masculino ( $A$ a $D$ ) e feminino ( $E$ a G)

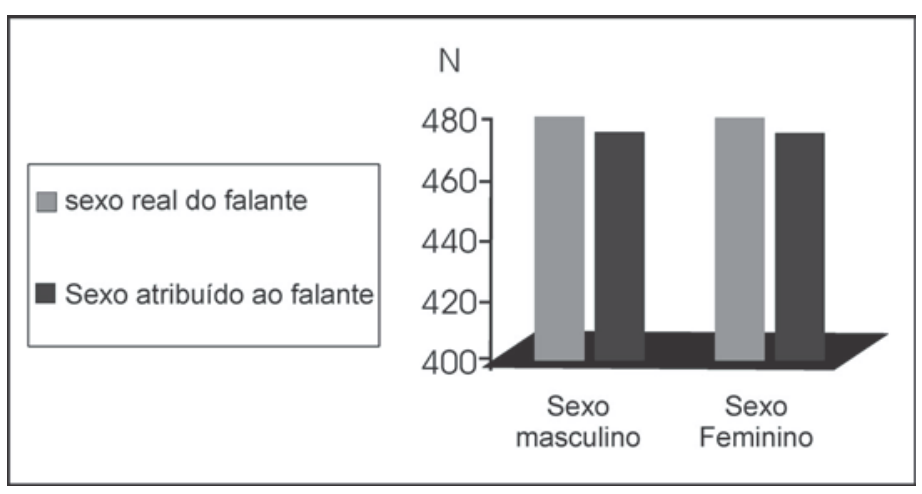

Figura 3 - Julgamento perceptivo-auditivo das amostras de fala quanto ao sexo real e ao sexo atribuído de 08 falantes do grupo estudado por 60 juízes 


\section{DISCUSSÃO}

Os dados apresentados são discutidos com relação aos valores de f0 para ambos os grupos estudados (homens e mulheres acima de sessenta anos de idade), além de comparação aos achados literatura para adultos jovens de ambos os sexos falantes do português ${ }^{25,26}$.

Os valores de fo encontrados para falantes do sexo masculino no vocábulo em início de sentença (Tabela 1) nas sílabas pré-tônica e tônica sugerem rebaixamento de valores médios de f0 e da faixa inferior de variabilidade para os falantes idosos em relação aos adultos jovens do mesmo sexo ${ }^{25,26}$.

Para os valores de f0 no vocábulo em final de sentença (Tabela 4) nas sílabas pré-tônica e tônica, ainda no sexo feminino, foi relacionado o maior número de ocorrências de ajustes de voz crepitante em relação à Tabela 2. Vale ressaltar que em finais de sentenças do tipo declarativa espera-se um declínio natural da emissão tanto em termos de freqüência, como de intensidade, sendo plausível a ocorrência de ajustes de voz crepitante, os quais também se fizeram presentes, ainda que em menor proporção, na população do sexo masculino. Os valores de desvio-padrão foram maiores para os homens, especialmente no contexto de início de frase, de forma que os valores de variabilidade situaram-se abaixo da média de f0 para os falantes adultos jovens do sexo masculino 25,26. Apesar da literatura reforçar maior incidência de alterações laríngeas na população masculina com avanço da idade ${ }^{1,2,8,18,21}$ e de correspondentes mudanças em parâmetros da voz, especialmente no sentido da elevação de fo 1,2,9,18,19, os achados do presente estudo indicaram direção oposta nos valores, em que apenas um dos falantes (D) revelou ligeira elevação de f0 para as emissões em início de sentença. Poucas diferenças estatisticamente significantes em relação às medidas de f0 da idade adulta foram encontradas.

Os valores de fo encontrados para falantes do sexo feminino nos vocábulos em posição de início e final de sentença (Tabelas 2 e 4) sugerem importante rebaixamento de valores médios de f0 em relação à população do mesmo sexo na idade jovem adulta, de forma que o limite de freqüência inferior estimado para adultos jovens ${ }^{25,26}$ é cerca de $30 \mathrm{~Hz}$ mais alto que o limite superior encontrado no presente estudo, com diferenças estatisticamente significantes para a maior parte das emissões avaliadas. A faixa da distribuição das medidas de f0 para a vogal em sílaba tônica no vocábulo em posição final de emissão chega a se assemelhar aos valores da faixa prevista para adultos jovens do sexo masculino ${ }^{25,26}$.

Mesmo diante de tais achados de valores rebaixados de f0, a maior parte dos falantes do sexo feminino em ambas emissões foi identificada como mulher e em faixa etária mais baixa que a sua real (Figura 3). Tais achados são consistentes com várias referências da literatura quanto ao rebaixamento de f0 para mulheres na faixa etária mais avançada ${ }^{1,2,10,17-19}$, em função de mudanças na estrutura laríngea , tais como atrofia do músculo vocal ${ }^{8}$, processo de ptose laríngea ${ }^{6,9}$, estiramento excessivo dos ligamentos de aparatos de suspensão ${ }^{9}$, a degeneração de gordura dos tecidos ${ }^{5}$, intensificação da ossificação das cartilagens laríngeas, que ficam mais rígidas e menos distensíveis ${ }^{6}$ e mucosa que se torna espessa ${ }^{1,6,8}$. De forma mais marcante, fatores como alterações hormonais podem estar relacionados ao agravamento da freqüência fundamental, principalmente a menopausa, que modifica as estruturas e as condições da mucosa, com favorecendo o aparecimento de edema ${ }^{8,21}$. Pode-se ainda mencionar o tabagismo ${ }^{5}$, referido em questionário por $\mathrm{H}$.

Cabe destacar que, na população estudada, outros parâmetros podem ter sinalizado sexo dos falantes, uma vez que, apesar do sensível rebaixamento das medidas de f0, a maio parte foi referida como sendo realmente do sexo feminino, de forma que a atribuição de sexo não pode ser creditada exclusivamente aos valores de f0, conforme apontam alguns estudos ${ }^{23,24}$. No presente estudo, não foram encontradas confusões entre sexos atribuídos aos falantes conforme anteriormente mencionado ${ }^{1,17}$.

Observa-se rebaixamento da f0 nos sujeitos idosos em ambos os sexos. No sexo masculino, a faixa do desvio padrão alcança a média de f0 dos jovens e o mesmo não ocorre no feminino. Diante disso, os falantes do sexo feminino revelaram maiores mudanças nos valores de f0 em relação à idade, em comparação aos adultos jovens do mesmo sexo.

Tais dados devem ser considerados no contexto de que a casuística é pequena e talvez o aumento do número de sujeitos revelasse outros efeitos. No presente estudo, o rebaixamento de valores de f0 ocorreu de forma mais intensa em finais de sentenças. Destaca-se para esta etapa a importância de investigação de medidas de f0 associadas a julgamentos da percepção auditiva, bem como a mensuração de f0 em diferentes contextos dentro da sentença, uma vez que a mensuração de f0 é dependente de variação melódica e, valores médios de longos trechos de emissão podem apenas refletir variações de parâmetros prosódicos e não propriamente a fo habitual do falante.

Outro fator importante a ser discutido refere-se ao fato de que os falantes não foram julgados como representantes de faixa etária acima de sessenta anos. Em sua maioria, os foram atribuídas diferenças inferiores em torno de vinte anos da idade real em relação a atribuída (B , D, E, G, H). Neste ponto, cabe mencionar hábitos, como fumo pregresso para $\mathrm{H}$, do grupo do sexo feminino, C que ainda fuma, represen- 
tante do grupo masculino. Além disto, B e H são participantes de coral e $\mathrm{G}$ e H praticam atividade física regular, fatores descritos como relacionados à longevidade vocal ${ }^{1,5}$. Deve-se salientar que o ritmo das manifestações relativas ao envelhecimento é altamente individualizado ${ }^{7}$.

Os resultados ressaltam a importância de abordagem de particularidades de emissão vocal em indivíduos idosos, não sendo possível generalizar padrões de f0 para grupos de falantes de sexo feminino e masculino. Sendo o envelhecimento descrito como processo individualizado, as manifestações no aparelho fonador seguem tais tendências. Estudos promissores neste campo concentram-se na integração de padrões acústicos com descritores perceptivos e fisiológicos da qualidade vocal na referida população.

\section{CONCLUSÃO}

Diante dos resultados apresentados no presente estudo, foi possível concluir que há diferença das médias de valores de f0 nos idosos entre os sexos dos falantes, com as mudanças em relação à faixa do adulto jovem concentradas no sexo feminino (rebaixamento), para avaliação de estímulos silábicos em diferentes contextos (sílabas tônica e pré-tônica).

Os julgamentos perceptivo-auditivos revelaram que os falantes foram identificados corretamente quanto ao sexo, o que correspondeu à diferença do valor em média de f0 entre os sexos. Quanto ao julgamento da idade dos falantes, foram atribuídas em sua maioria, idades abaixo da real, com diferenças maiores que vinte anos de idade.

\section{ABSTRACT}

Purpose: to investigate fundamental frequency (f0) in elderly people of both genders, discussing correlations to the perceptual sphere (gender and age bracket). Methods: 4 male and 4 female subjects were selected aging from 60 to 76 years, without any disturbances in the vocal tract, had their speech samples (standard text) recorded in two repetitions. The f0 values were measured in vowel [a] in stressed (S) and pre-stressed (PS) syllables. The samples were also submitted to perceptual analysis, by 60 judges, in order to evaluate speaker's gender and age. Results: average f0 values in PS syllables were $114.14 \mathrm{~Hz}$ at the beginning of sentences and $102.71 \mathrm{~Hz}$ at the end for male subjects and $151 \mathrm{~Hz}$ at the beginning and $146.87 \mathrm{~Hz}$ at the end for female subjects. For S syllables the values were 117.42 $\mathrm{Hz}$ at the beginning and $92.85 \mathrm{~Hz}$ at the end for male subjects and $175 \mathrm{~Hz}$ at the beginning and 122.50 $\mathrm{Hz}$ at the end for female subjects. There was a significant difference among f0 measures for both genders, as well as among the speakers of the same gender regarding the adult age group. All speakers were judged correctly in gender, with age being referred to as below the real one. Conclusion: there was a significant difference in f0 values between gender in elderly subjects, where female subjects presented lower values comparing to younger subjects in the same gender. These data did not seem to interfere with judgments of gender and age bracket.

\section{KEYWORDS: Speech Acoustics; Aged; Voice; Gender Identity; Auditory Perception}

\section{REFERÊNCIAS}

1. Soares LT. Comparação do padrão vocal de idosos com e sem doença pulmonar obstrutiva crônica [mestrado]. São Paulo (SP): Universidade Federal de São Paulo; 2001.

2. Campos CM. Impacto da voz na qualidade de vida de mulheres idosas [mestrado]. São Paulo (SP): Pontifícia Universidade Católica de São Paulo; 2001. 3. Behlau MS. Presbifonia: envelhecimento vocal inerente à idade. In: Russo IP. Intervenção fonoaudiológica na terceira idade. Rio de Janeiro: Revinter; 1999. p. 25-43. 4. Ramig LO, Gray S, Baker K, Corbin-Lewis K, Buder $E$, Luschei $E$, et al. The aging voice: a review, treatment data and familial and genetic perspectives. Folia Phoniatr Logop. 2001; 53(5):252-65.

5. Ferreira LM. Aprimoramento vocal na terceira ida- de. In: Pinho SMP. Fundamentos em fonoaudiologia: tratando os distúrbios da voz. Rio de Janeiro: Guanabara-Koogan; 1998. p. 115-7.

6. Costa HO, Andrada e Silva MA. Voz cantada: evolução avaliação e terapia fonoaudiológica. São Paulo: Lovise; 1998.

7. Ribeiro A. Aspectos biológicos do envelhecimento. In: Russo IP. Intervenção fonoaudiológica na terceira idade. Rio de Janeiro: Revinter; 1999. p. 1-11.

8. Biase NG, Cervantes O, Abrahão M. A voz no idoso. Acta Awho. 1998; 17:70-2.

9. Wilder CN. Vocal Aging. In: Transcriptions on the seventh symposion care of the professional voice. New York; 1978.

10. Linville SE, Rens J. Vocal tract resonance analysis of aging voice using the long term average spectra. $J$ Voice. 2001; 15(3):323-30. 
11.Sato K, Hirano M. Age-related changes of the macula flava of the human vocal fold. Ann Otol Rhinol Laryngol. 1995; 104(11):839-44.

12.Paulsen F, Kimpel M, Lockemann U, Tillmann B. Effects of ageing on the insertion zones of the human vocal fold. J Anat. 2000; 196(Pt 1):41-54.

13.Sato K, Hirano M, Nakashima T. Age-related changes of collagenous fibers in the human vocal fold mucosa. Ann Otol Rhinol Laryngol. 2002; 111(1):15-20.

14. Hirano S, Bless DM, Río AM, Connor NP, Ford $\mathrm{CN}$. Therapeutic potential of growth factors for aging voice. Laryngoscope. 2004; 114(12):2161-7.

15.Ximenes Filho JA, Tsuji DH, Nascimento $\mathrm{PH}$, Sennes LU. Histologic changes in human vocal folds correlated with aging: a histomorphometric study. Ann Otol Rhinol Laryngol. 2003; 112(10):894-8.

16. Soyama CK, Espassatempo CDL, Gregio FN, Camargo ZA. Qualidade vocal na terceira idade: parâmetros acústicos de longo termo de vozes masculinas e femininas. Rev CEFAC. 2005; 7(2):267-79. 17. Linville SE. The aging voice. In: Kent RD, Ball MJ. Voice quality measurement. San Diego: Singular; 2001. p. 359-62.

18. Behlau MS, Pontes P. Avaliação e tratamento das disfonias. São Paulo: Lovise; 1995.

19. Carbonell J, Tolosa F, Juan E. Presbifonía: estudo de los parámetros acusticos de normalidad. Acta Otorrinolaring Esp. 1996; 47:295-9.
20. Ryan W, Burke K. Perceptual and acoustic correlates of aging in the speech males. J Commun Dis. 1974; 7(2):181-92.

21. Kahane JC. Connective tissue changes in the larynx and their effects on voice. J Voice. 1987; 1:27-30.

22. Polido AM, Martins M, Hanayama EM. Percepção do envelhecimento vocal na terceira idade. Rev CEFAC. 2005; 7(2):241-51.

23. Honorof DN, Whalen DH. Perception of pitch location within a speaker's F0 range. J Acoust Soc Am. 2005; 117(4 Pt 1):2193-200.

24. Gelfer MP, Mikos VA. The relative contributions of speaking fundamental frequency and formant frequencies to gender identification based on isolated vowels. J Voice. 2005; 19(4):544-54.

25. Pegararo-Krook MI, Castro VC. Normative speaking fundamental frequency (SFF) characteristics of brazilian male subjects. Braz J Med Biol Res. 1994; 27(7):1659-61.

26. Castro VC, Pegararo-Krook MI. Características da freqüência fundamental da fala de indivíduos do gênero feminino, falantes do português brasileiro. PróFono. 1994; 6(2):5-7.

27. Camargo Z, Madureira S, Tsuji DH. Analysis of dysphonic voices based on the interpretation of acoustic, physiological and perceptual data. In: $6^{\text {th }}$ International Seminar on Speech Production. Proceedings. Sydney; 2003.
RECEBIDO EM: 26/10/2005

ACEITO EM: 11/04/2007

Endereço para correspondência:

Rua Taguá, 305 ap. 303

São Paulo - SP

CEP: $01508-010$

Tel: (11) 47482149

E-mail:x_erika@yahoo.com 